\title{
Massini-Correas, Carlos I., Alternativas de la ética contemporánea. Constructivismo y realismo ético, Madrid, Rialp, 2019, 216 pp.
}

Robert Alexy sostuvo hace algún tiempo que "en la discusión actual compiten sobre todo tres concepciones de la razón práctica o de la racionalidad práctica que, tomando como punto de referencia los modelos históricos, pueden ser llamadas aristotélicas, hobbesianas y kantianas. Si a esto se le suma la concepción crítica del concepto de razón práctica sostenida por Nietzsche, se obtiene un común denominador de estas concepciones [...]"1. Hablar de razón práctica supone ocuparse de aquellos ámbitos en los que está comprometido el obrar humano, cuya especificidad se enraíza y fundamenta en su carácter libre, en cuanto lo obrado es fruto de la deliberación y elección consciente. Los campos propios de la razón práctica son la ética, la política, la economía y el Derecho; éstos interactúan en un proceso que transita desde el plano individual de la existencia -en el caso de la ética- hacia el plano comunitario -en el caso de la política, la economía y el Derecho-. De modo que no hay discusión que se plantee en el ámbito general de la ética que no proyecte sus efectos, directos o indirectos, en los otros.

En este contexto, y en este proceso de trascendencia del plano individual hacia el social, una de las nociones más significativas que se yergue como consecuencia de la interacción comunitaria es la de los derechos, entendidos en términos de Derechos Subjetivos, facultades o potestades. El profesor de Oxford, John Finnis, en su obra maestra, Natural Law and Natural Rigths, escribió, a propósito de las listas de derechos consagradas en las Declaraciones Internaciones de Derechos Humanos, que un simple examen de ellas permite vislumbrar "los contornos del bien común, los distintos aspectos del bienestar individual en la comunidad. Lo que la referencia a los derechos aporta en este esbozo es simplemente una expresión enfática de lo que está implícito en el término bien común"2.

1 Alexy, R. (1994). El concepto y validez del derecho. Trad. J. M. Seña. Barcelona. Gedisa, p. 133.

2 Ibíd., 214. 
En el plano ético no podemos ignorar que estamos frente a un panorama de fragmentación respecto del cual el debate iusfilosófico contemporáneo no ha resultado impermeable, sino que ha proyectado sus efectos sobre el discurso jurídico en general y sobre el concepto de derechos en particular. En este sentido, señala acertadamente Pilar Zambrano que el "juego del lenguaje" de los principios y derechos fundamentales se ha fragmentado al compás de la fragmentación social y cultural ${ }^{3}$. En consecuencia, no resulta temerario afirmar que esta situación ha dado lugar a un proceso que puede conducir a una progresiva disolución o desvanecimiento de la idea de Derechos Humanos, en la medida en que la misma se ha convertido en un concepto altamente manipulable según cuáles sean los intereses ideológicos o políticos en pugna.

Este fenómeno reconoce su origen en la dicotomía entre realismo y constructivismo ético, que es el eje central del libro del profesor Massini y que se verifica históricamente en el momento en que el hombre eleva la autonomía de la voluntad a la jerarquía de autoridad soberana en el juzgamiento de la conducta humana, renunciando a todo marco de referencia normativo objetivo proveniente de la reflexión metafísica propia del realismo ético. Así, cada concepto que desde la perspectiva ética realista nació con una referencia de objetividad fundada en la inteligibilidad intrínseca y evidente de la realidad designada, hoy navega en la descontrolada e incontrolable marea de concepciones morales, éticas, políticas e ideológicas que cuestionan aquel núcleo rígido originario y aprehensible que sirvió de guía en el proceso que condujo a la formulación de los conceptos centrales de la tradición central de la ética.

La descripción antecedente resulta particularmente aplicable al concepto de Derechos Humanos, en cuyo origen histórico y concreción jurídica se advierte esta referencia objetiva, sobre la base del reconocimiento de un acervo común fundado en la dignidad humana. Se podría afirmar que, teniendo en cuenta el contexto histórico de posguerra en que surgen las Declaraciones de Derechos del siglo XX, subyace en el concepto de esos derechos un proceso en virtud del cual -siguiendo aquí los aportes de los filósofos del lenguaje, Putnam y Kripke-se le atribuyó prioridad a "referencia sobre el significado" 4 .

3 Zambrano, P. (2014). "Principios fundamentales e inteligibilidad del derecho. Entre el realismo semántico y una teoría objetiva del bien y de la acción”. En Dikaion, Volumen 23, Número 2. Colombia. Chía, 423-445.

4 Sobre el punto, véase: Kripke, S. (1972). "Name and Necessity”. En Davidson, D. y Hartman, G. (eds.). Semantics of Natural Language. Netherlands. Sipringer, 253; Putnam, H. (1975). "The Meaning of the Meaning”. En Gunderson, K. (ed.). Mind, Language and Reality. Cambridge. Cambridge University Press, 131. 
Sin embargo, el panorama actual de la situación sugiere que el concepto de Derechos Humanos habría atravesado la saga de los distintos enfoques constructivistas que estudia el profesor Massini en este libro, en una suerte de evolución histórica que ha ido socavando su núcleo rígido inteligible y que los hacía racionalmente para terminar asentándose en una concepción diluida que parece decantar en una noción residual que obedece al enfoque constructivista crítico propio del nihilismo contemporáneo.

Ciertamente, "en los saberes referidos prácticamente a la conducta humana -escribe Massini a propósito de este proceso-, la fuente de los contenidos valorativos, normativos o principiales, no es el conocimiento receptivo de ciertos fenómenos humanos (experiencia), sino la mera construcción de la razón" . En efecto, tanto en las variantes neo-kantianas como neo-humeanas, el presupuesto central del constructivismo radica en la "afirmación de dos tesis principales: (i) la imposibilidad de conocer la existencia de realidades en sí más allá de nuestros actos de pensamiento; (ii) que todo conocimiento es una mera construcción de nuestra mente o nuestro lenguaje (o de ambos)"6. Por su parte, escribe Gadenne que "el mundo es considerado una construcción social, producto de la acción social, en la que tienen un papel central los actos del lenguaje. La instancia constructora no es aquí el individuo ni tampoco, menos aún, el cerebro, sino en cada caso una comunidad lingüística determinada"7.

Aplicando esta lógica al concepto de Derechos, el mismo será resultado de un proceso de formulación cuya principal característica se encuentra ligada a la forma o procedimiento en que se construye la noción de bien a proteger o reconocer mediante el Derecho. Así, Massini muestra que, en el caso del constructivismo neo-kantiano, el bien se determina a partir de ciertas estructuras de la razón práctica; mientras que en la variante neo-humeana, la noción de bien se vincula con determinadas preferencias o deseos del sujeto actuante.

En el caso del constructivismo práctico-procedimental el ejemplo paradigmático es el propuesto por John Rawls en su Teoría de la Justicia, en la que se plantea que el bien se determina solo según "un proceso -en palabras del profesor Massini- idealizado de deliberación, elección y acuerdo racional, y se constituye por lo que los agentes acordarían en determinadas condiciones idealizadas o hipotéticas de deliberación racional"8. Finalmente, en el caso del constructivismo crítico, la razón práctica es sustituida por

5 Massini-Correas, C. I. (2019). Alternativas de la ética contemporánea. Madrid. Rialp, 44.

6 Darós, W. “De qué constructivismo hablamos?”. En williamdaros.files.wordpress. com/2009/08.

7 Gadenne, V. (2006). Filosofía de la Psicología. Trad. Romero, D. Barcelona. Herder, 233.

8 Massini-Correas, C. I. Alternativas... Ob. cit., 63. 
la razón crítica, encargada de denunciar y develar relaciones de poder encubiertas en el discurso ético. Ciertamente, los autores enmarcados en las corrientes críticas comparten la tesis de que "la razón nada tiene que hacer en el ámbito de las realidades [ético] jurídicas, las que no serían sino la canonización enmascarada de relaciones de mero poder, de pulsiones eróticas, de poderes económicos" 9 .

El caso más emblemático de constructivismo crítico en el ámbito iusfilosófico se verifica en la propuesta del exponente quizás más radical de la corriente conocida como Critical Legal Studies Movement: Duncan Kennedy. En su propuesta iusfilosófica este autor ha enfatizado su carácter esencialmente ideológico del Derecho. "Afirmo - escribe Kennedy- que los proyectos ideológicos que nos resultan familiares [...] resultan ampliamente creación judicial del Derecho, pero que el trabajo jurídico ideológicamente orientado es diferente del trabajo legislativo, ideológicamente orientado"10. En consecuencia, en la tarea de creación del Derecho -y en el reconocimiento de los derechos como parte de esa creación-, la única constante que cabe predicar es la indeterminación. En otros términos, para este autor, todo intento de fundamentar la justicia o los Derechos Humanos sobre la base de alguna noción objetiva de bien, no es más que un recurso retórico que sirve para enmascarar intereses subyacentes, y que - una vez develados- solo ponen en evidencia la propia indeterminación; con ello, su ininteligibilidad. De ahí la relevancia de esta nueva obra del profesor Massini-Correas, en la medida en que posibilita la recuperación de criterios de objetividad tan necesarios para la justificación de conceptos iusfundamentales, mediante la identificación de dos corrientes principales: la constructivista y la realista, estrictamente contradictorias y excluyentes una de otra, sin que pueda pensarse una solución intermedia entre estas propuestas centrales.

Además, al estudiar el constructivismo ético, Massini-Correas explica que quienes se enmarcan dentro de este enfoque sostienen una concepción de realismo radicalmente falsa. En efecto, para estos autores, el realismo sostiene una concepción ética según la cual sería posible reflejar la totalidad de soluciones morales, con sus circunstancias, mutaciones históricas, intenciones y detalles operativos exclusivamente a partir de la aprehensión de ciertas realidades ("hechos") morales preestablecidos, solo verificables en un mundo veleidoso e inexistente. $\mathrm{Y}$ como este mundo es irreal, sostienen los constructivistas, el realismo es falso. El problema principal de esta visión radica en que no existe ningún autor "realista" que sostenga semejante

9 Massinni-Correas, C. I. (2006). La ley natural y su interpretación contemporánea. Pamplona. EUNSA, 184.

10 Kennedy, D. (2010). Izquierda y Derecho. Ensayos de teoría jurídica crítica. Trad. Guillermo Moro. Buenos Aires. Siglo Veintiuno, 154. 
sinsentido, sino que sostiene una visión matizada en la que participan aprehensiones de la realidad humana compleja confluyendo valoraciones éticas, consideraciones históricas, situacionales e intencionales, juicios prudenciales, deliberaciones e imperativos. De este modo, el autor demuestra que los constructivistas están "ladrando al árbol equivocado".

Asimismo, en el abordaje que hace el autor de la fundamentación realista, se destaca la división de interpretaciones y modos de abordaje de la q. 94, a. 2 de la Summa Theologiae I-II, donde el Aquinate resume su explicación de la ley natural. Según Massini, estas interpretaciones serían básicamente tres: (i) la derivacionista, según la cual las normas de la ley natural se inferirían directamente de los atributos de la naturaleza humana, conocidos teóricamente; (ii) la inclinacionista, que afirma que las normas de la ley natural se derivan de la inclinaciones naturales del hombre; y (iii) la intuicionista, que sostiene que los preceptos de la ley natural se siguen de los bienes humanos básicos. Massini-Correas defiende, con sólida argumentación, que en rigor esas tres interpretaciones no son excluyentes sino complementarias y que dependen de la perspectiva de abordaje que se adopte para alcanzar el conocimiento de esos principios.

Finalmente, en el Apéndice del libro, y sobre la base del aporte filosófico de la pensadora inglesa Elizabeth Anscombe, Massini identifica un posible resurgimiento de la ética de las virtudes de estructura aristotélica. En definitiva, se trata de una valiosa aportación al esclarecimiento de líneas matrices de la ética contemporánea, a la vez que supone una sólida y rigurosa defensa de los lineamientos éticos fundamentales propios del realismo clásico. La bibliografía utilizada y citada por Massini es especialmente rica y relevante, la exposición es breve a la vez que suficiente y la argumentación es especialmente sólida y convincente. Se está, por lo tanto, frente a un libro que constituye una aportación valiosa a los debates contemporáneos de la filosofía moral, a la vez que una contribución cualificada para la recuperación, revalorización y reformulación del realismo ético clásico y sus contribuciones al desarrollo de los saberes prácticos.

ELIANA DE ROSA 